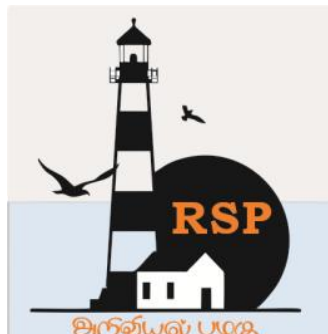

INTERNATIONAL RESEARCH JOURNAL ON ADVANCED SCIENCE HUB

ISSN : $2582-4376$
Open Access

RSP SCIENCE HUB

(The Hub of Research Ideas)

Available online at www.rspsciencehub.com

Special Issue of Second International Conference on Advancements in Research and Development (ICARD 2021)

\title{
Home Appliances Service Management
}

Mothilaal $K A^{1}$,Mohan Raj $M^{2}$,Mahesh Kumar ${ }^{3}$,Poonkodi $P^{4}$,Sangeetha $K^{5}$

${ }^{1,2,3} U G$ Scholar, Department of Computer Science and Engineering, SNS College of Technology, Coimbatore, India.

${ }^{4,5}$ Assistant Professor, Department of Computer Science and Engineering, SNS College of Technology, Coimbatore, India.

mothimonish1999@gmail.com ${ }^{1}$,mohan30raj19@gmail.com², sakarakuttymass143@gmail.com³, poonkodi.cse@gmail.com ${ }^{4}$,sangithaprakash@gmail.com ${ }^{5}$

\begin{abstract}
In the present scenario, people are buried up in a heavy work culture that they forget about the maintenance of their house. The leakage in pipe or fixing furniture, no one really has time to fix it on their own. Finding a plumber or carpenter nearby has also become a hectic task as they are not ready to come home for a small work. This is where our system will come to aid. We provide a one stop system that provides many services like plumbing, electronics repair, gas stove repairing, $R O$ servicing and electrical services, home cleaning, carpentry services, machine services, home painting, tutors packers and movers, home design and construction, party and event, health and wellness at your doorstep in just one click. Not just that we also give you access to no of repair persons, cleaners, electricians, painters to whenever something needs to be fixed at home. You can choose the particularity of service required by uploading the image of desired specification on your mobile and you will immediately receive a confirmation email with timing. We provide services as part time and full time job, the servicer can choose according to their convenience. Our system is versatile as service can be booked from everywhere to anywhere you desire.
\end{abstract}

Keywords: service management, Node.js.

\section{Introduction}

According to, India's smart smartphone businesses are rising at a rapid pace. Almost $72 \%$ of cell phone users have smart phones, and $52 \%$ have access to the internet through edge, $3 \mathrm{G}$, or GPRS. All types of groups are increasingly turning to modern day gadgets as a result of the widespread uses of clever phones. Orders are now placed with a few clicks on mobile phones, and desired items are delivered to the door steps. People are searching for jobs and customers are looking for services as quickly as possible in today's gadgetfriendly environment.The new development in the business of on-demand applications is services. The website can be competitive with proper market analysis, the inclusion of key features, and effective marketing. Assuming that we all want an Iron in our lives, demand for Home Services websites will increase. The system provides services such as plumbing, computer repair, gas stove repair, RO maintenance and electrical services, home cleaning, carpentry services, equipment services, home painting, tutors, packers and movers, home design and construction, party and event planning, and health and wellness to meet the needs of customers. The dependable home services website with skilled and trained staff will quickly repair and fix everything in and around your home. Rapid urbanisation, increasing wages, and a surplus of low-cost jobs exacerbate problems. 


\section{Literature survey}

There are numerous online home service systems available, which are briefly explored in this survey. Mr. Right is an app that started out as a way to link only the ubran areas of specific cities like Delhi, Noida, Gurgaon, Faridabad, Ghaziabad, Mumbai, Hyderabad, Pune, Bengaluru, Chandigarh, and Jaipur[1].Time saverz is one of the web-based home service systems where customers can earn incentives for services rendered and receive a refund if they are not pleased. Delhi, Noida, Gurgaon, Hyderabad, Bangalore, Pune, Mumbai, and Chennai[2] all provide this facility. Urban Clap has offered a range of exclusive services. They have, however, provided those services in cities such as Mumbai, Delhi, Chennai, and Bangalore. This method was used to train over 10,000 professionals[3].House Joy also provides benefits to its staff and clients, such as free five-year insurance and free rework, which has helped them build a loyal customer base. It may employ professionals to clean the house, manage pests, paint, carpentry, and plumbing, as well as repair appliances and electrical components. The majority of the services are rendered in Bangalore [4].

\section{Existing System}

Consumers that need household utilities can access the fine print of service providers via the existing networks. The system provides gas, plumbing, and electrical services, among other things. Users can look at the programmes offered across the system and request them from the individual providers. The user must first register in order to access the system's services. The device acts as a link between the consumer in need of services and the service provider who can deliver them. Users can only get the fine print about service providers under the current system; they do not have the option to register for the services they need, and therefore do not have the ability to monitor those services. Users may provide input on the services that they have received. The modules that are currently available in the framework are listed below.

\subsection{Admin Module}

The administrator has complete access to the device. He manages user login information, assigns access rights to users, manipulates data, and completes all transactions. The system's administrator is the system's most powerful person.

\subsection{Service Provider}

On this website, service providers must first register and then login in order to access the services that are available to 11 registered users. The services that a service provider can offer can be recorded. We have a map for the service provider to locate himself on this website. To provide services, the service provider travels to the customer's location.

\subsection{Customer}

The customer registers on this website and then $\operatorname{logs}$ in, after which the user searches for a specific service and receives a list of services available on our website. After that, the customer chooses the service and submits a request for it.

\subsection{User Module}

This module provides information on the resources available. The purchasers would be able to access the service provider's address for the services that have been rendered. The services can also be bookmarked by users. They will then be prepared to view the programmes if they have the opportunity.

\subsection{Feedback Module}

Customers may provide input and suggestions about the services that have been provided as well as the service providers. Admin may take the necessary decisions based on the grievances and opinions that have been received from the users.

\section{Proposed system and architecture}

Our proposed project is a web application that uses NODE JS as the front end, SQL Server as the back end, and MANGO DB as the database to help users find essential services such as plumbing, electronics repair, gas stove repair, RO servicing and electrical services, home cleaning, carpentry services, machine services, home painting, tutors, packers and movers, home design and construction. Home service providers should register on this website and provide basic information such as their contact information and original government identification. This website allows users to register by providing basic information such as their name, age, gender, address, phone number, government evidence, and email address. After that, they can access the required services by logging in with their username and password. By noting the location 
www.rspsciencehub.com

and feedback, the user will find a service provider. When a user requires a specific service, they may submit a request. Service providers receive the user's request and can communicate with them by viewing their basic information. The administrator serves as a connection between the user and the provider. The administrator has access to the entire database of providers and users. This enables the user to receive services without delay and eliminates the need for the user to rely on others to identify service providers. The user may express their dissatisfaction with the services provided by posting their complaints and feedback. Administrators will view the reports that have been left and take appropriate action in response to the complaints. User, service provider, and admin logins are all part of the scheme. The customer will scan the service and retrieve it from the database after logging in with his credentials. The service provider can add and access the service after logging in with their credentials. When a service is added, it is saved in the database and can be retrieved whenever the service is required. The administrator has the ability to add service providers and access user information.

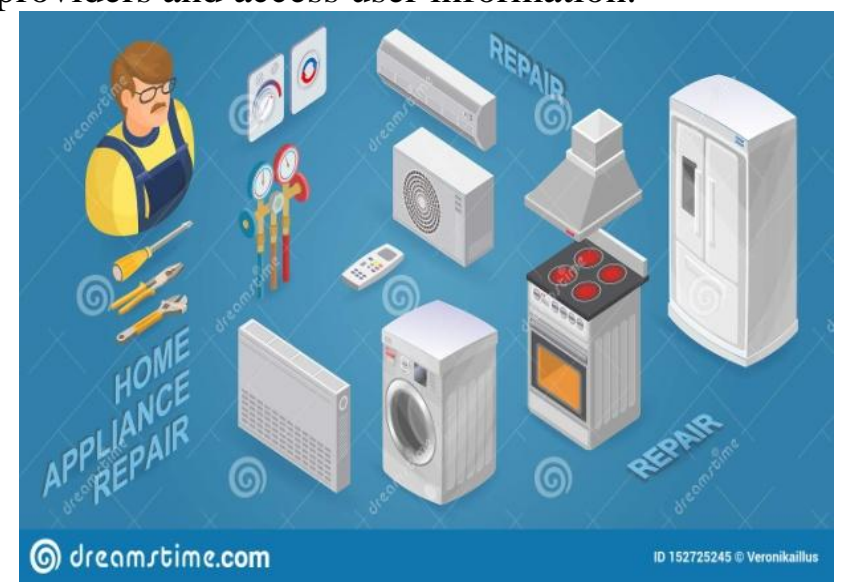

Fig.1 Repair stock illustration

\subsection{Modules in the System Proposed}

The proposed device consists of three modules. In this section, the functionalities of these three modules are discussed.

\subsection{1 on Demand Home Service System Login Page}

Admin, customer, and service provider logins are also included in the scheme. The registration process must be completed first in order to access the various functionalities. The various features available in the system can be accessed after the registration process is completed.

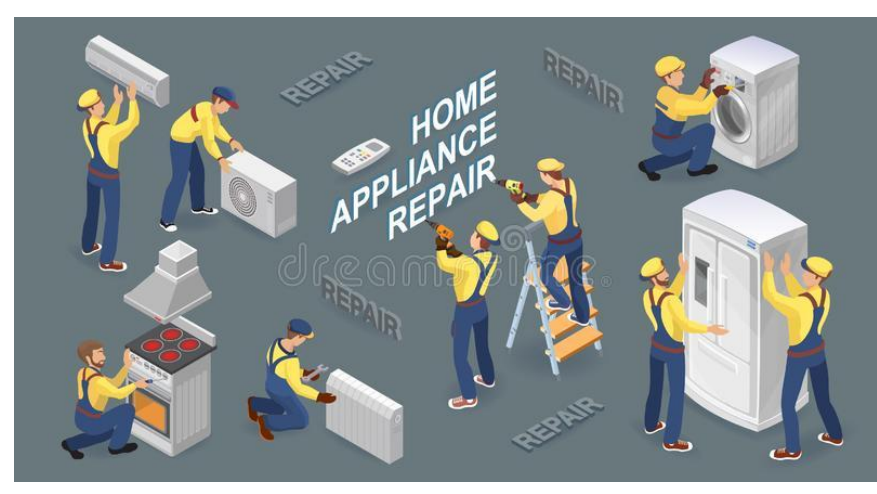

Fig.2 Repair isometric workers

4.1.2 on Demand Home Service System Admin Page

The admin module contains information about users, available resources, and service providers. Admin has the authority to change, add, or remove specific services or service providers if they violate the principles. They match the user with the provider based on the customer's request. By sending the status of the requested service (shown in fig.3), the admin acts as an intermediary between the providers and the users. This enables users to demand immediate updates.

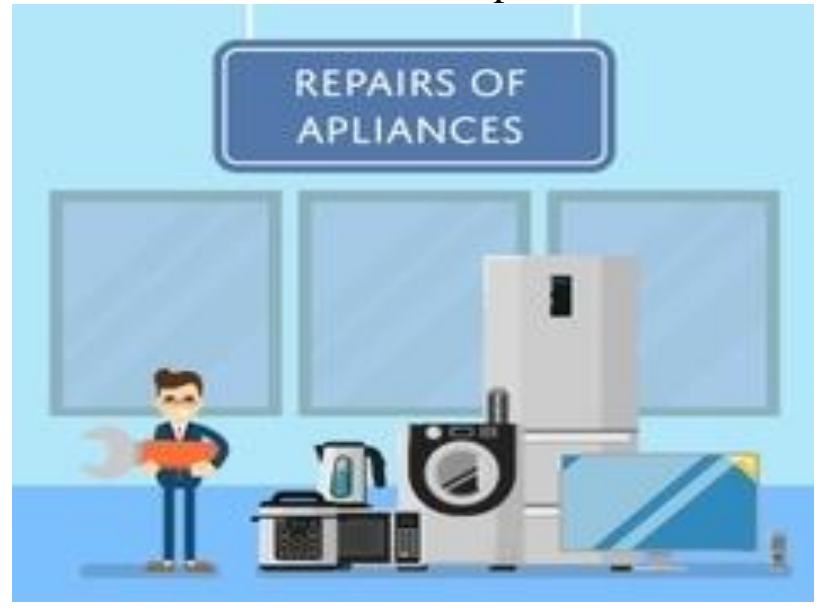

\section{Fig.3 Vector image \\ 4.1.3 on Demand Home Service System Services Page}

Customers who wish to schedule a service can do so by logging into their account. The framework includes a specialised interactive interface that provides a smart way of holding a service, in which users are asked to supply information regarding the services they need. Customers may use the chat bot to explain their doubts about specifics if necessary. When a service is rendered, the request is sent, and the user is directed to the payment page in Figure 4 to complete the payment process. 
www.rspsciencehub.com

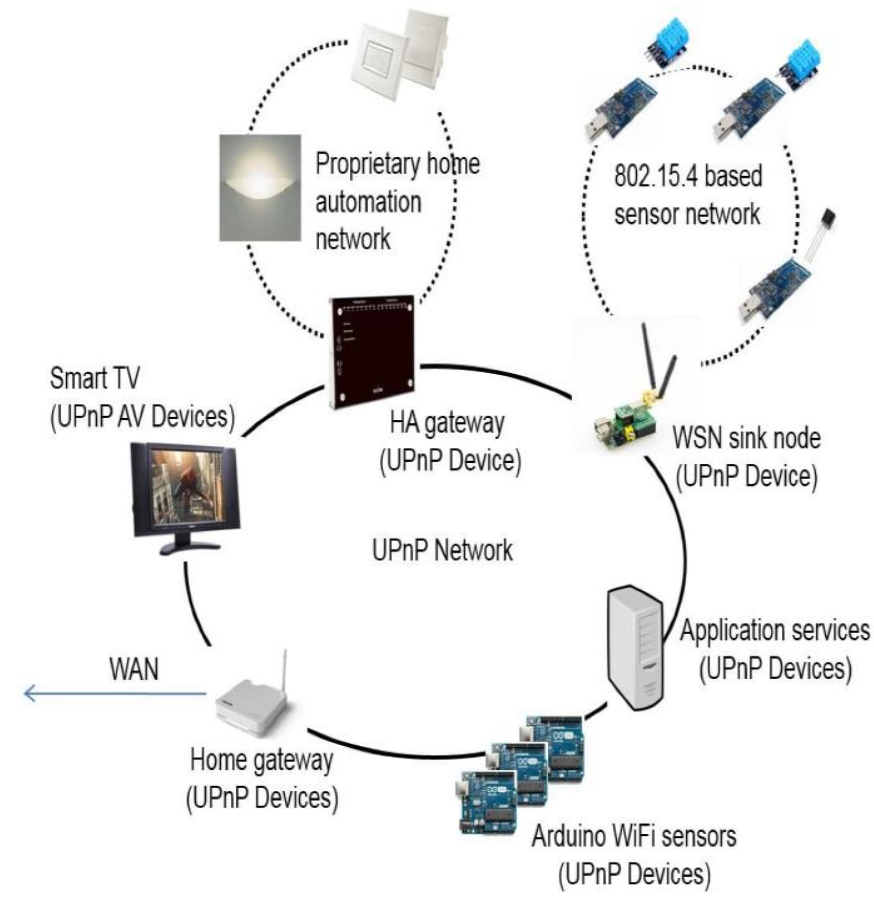

\section{Conclusion}

Fig.4 Resource oriented service

To alleviate the pressure of locating suitable service providers, this application offers comprehensive information that enables users to have their needs met quickly. Unlike other applications, this one includes a chat bot that assists users in clarifying their questions. As a result, this programme tends to be more alive than the current method.

\section{Reference}

[1]. SheetalBandekar, AvrilD'Silva, “Domestic Android Application for Home Services" International Journal of Computer Applications, ISSN No.0975 - 8887, Volume 148 - No.6, August 2016.

[2].N.M.Indravasan,AdarshG,ShruthiC,Shanthi "An Online System for Household Services" International Journal of Engineering Research \& Technology (IJERT), ISSN: 2278-0181, May 2018.

[3]. ShahrzadShahriari, MohammadrezaShahriari, Saeidgheiji. " Ecommerce And It ImpactsonGlobal Trend And Market" International Journal of ResearchGranthaalayh. Vol.3 (Iss.4): April 2015

[4].Bo Zhang, Ruihan Yong, Meizi Li, Jianguo Pan, JifengHuanglaa,“ A Hybrid Trust Evaluation Framework for E-commerce in Online Social Network: "2169-3536, IEEE. Translations and content mining are permitted for academic research, 2016.
Volume 03 Issue 03S March 2021

[5]. ChenggangZhen,Peng Cheng. "Construction of campus trading platform based on third-party online payment" 2nd International Conference on Industrial and Information Systems, IEEE, 2010.

[6].SujitKumarBasak,IreneGovender."Examining the Impact of Privacy, Security, and Trust on the TAM and TTF Models for Ecommerce Consumers: A Pilot Study", IEEE, 2009.

[7].CAlYrnn-ping, WANG Yu-ying, "Simple Said about Online Payment Risks and Preventive Measure",China located International Conference on Information Systems for Crisis Response and Management, IEEE, 2010.

[8].DejanKovachev and Ralf Klammadriano, "Beyond the Client Server Architectures: A Survey of Mobile Cloud Techniques", workshop on mobile computing in 2011.

[9].Teddy Mantoro, AdmirMilišic, Media A. Ayu, "Online Payment Procedure Involving Mobile Phone Network Infrastructure and Devices ", IEEE, 2010.

[10]. Cong Yin, "An empirical study on users' online payment behaviour of tourism website", IEEE 12th International Conference on eBusiness Engineering, 2015.

[11].T Bhuvaneswari, K P Keerthana, "Image Segmentation Based on Dilation and Erosion to Reduce Background Noise", International Journal of Modern Trends in Engineering and Science, Volume 3, Pages 245-250, 2016.

[12].KP Keerthana, K Kavitha, "Comparative Analysis of Fault Coverage Methods", Bonfring International Journal of Power Systems and Integrated Circuits, Special Issue Special Issue on Communication Technology Interventions for Rural and Social Development, Volume 2, Pages 110-113, 2012.

[13].C Ramadevi, V Vijayan, "Design of decoupled picontroller for quadruple tank system- International Journal of Science and Research, Volume 3, Issue 5,Pages 318-323, 2014.

[14].K Sundaravadivu, C Ramadevi, R Vishnupriya,"Design of Optimal Controller for Magnetic Levitation System Using Brownian Bat Algorithm, Artificial Intelligence and Evolutionary Computations in Engineering 
Systems, Springer, New Delhi, Pages13211329, 2016.

[15].K Pooventhan, P ArunMozhiDevan, C Mukesh Kumar, R Midhun Kumar, "IoT Based Water Usage Monitoring System Using LabVIEW", Springer, Cham Smart Technologies and Innovation for a Sustainable Future, Pages 205-212, 2019. 